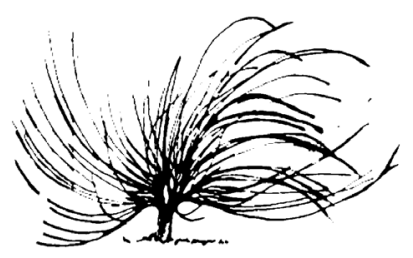

\title{
La enseñanza de la ética en Costa Rica
}

\author{
Yors Guillermo Solís Vargas ${ }^{1}$ \\ Ministerio de Educación Pública \\ Costa Rica \\ yors.solis.vargas@mep.go.cr
}

\begin{abstract}
Resumen
El siguiente ensayo tiene como objetivo realizar un análisis crítico de la enseñanza de la ética en Costa Rica. Para este fin, al inicio se va a conceptualizar brevemente esta disciplina y, durante el desarrollo del tema, se va a revisar y discutir algunos textos y planes de estudio en relación con ella y su atención durante las diferentes etapas de la educación formal en este país: preescolar, primaria, secundaria y universidad (particularmente de la Universidad Nacional). Al final, se concluirá con una reflexión de lo analizado.
\end{abstract}

Palabras clave: ética, moral, enseñanza, Costa Rica, educación.

\begin{abstract}
The following essay has the main aim of conducting a critical analysis of the teaching of Ethics in Costa Rica. At the beginning, this discipline will be briefly conceptualized. During the development of the topic, some texts and educational programs related to Ethics and its attention during formal educational stages in this country, such as elementary, secondary and higher education, specifically at Universidad Nacional, will be revised and discussed.
\end{abstract}

Recibido: 10 de febrero de 2020. Aprobado: 2 de setiembre de 2020.

http://dx.doi.org/10.15359/rep.16-1.2

1 Licenciado en Filosofía y estudiante de la Maestría en Pedagogía de la Universidad Nacional de Costa Rica. Trabaja para el Ministerio de Educación Pública desde 2011. Posee publicaciones en las revistas Praxis, Abra y Ensayos Pedagógicos de la Universidad Nacional, entre otras. https://orcid.org/0000-0002-0864-9010 
Finally, the essay will be concluded with a reflection of what was previously analyzed.

Keywords: ethics, morals, teaching, Costa Rica, education

\section{Introducción al concepto de ética}

$\mathrm{E}$

1 origen de la palabra "ética" proviene del griego antiguo $\grave{\eta} \theta \imath \kappa o ́ \varsigma$

(éthikos) que significa moral, y este vocablo, a su vez, deriva del

término $\dot{\varepsilon} \theta o \varsigma$ (éthos), el cual se puede entender como costumbre

o modo de ser de las personas. Las palabras "ética" y "moral" estaban contenidas bajo una misma etimología (éthikos) en la Grecia antigua, pero los romanos la tradujeron como moralis, vocablo que deriva del latín mos, moris que puede entenderse también como costumbre; y así fue como "moral", adquirió una fuente propia del latín, distinta a la griega éthikos.

La ética como estudio, teoría o, como actualmente, algunos la han llamado, ciencia de la moral, inicia en occidente con los sofistas, quienes, según MacIntyre (1998), fueron los primeros en intentar explicar cómo vivir bien y con eficacia en la ciudad-estado de Atenas, Grecia antigua; sin embargo, es con Sócrates - a quien se le ha conocido como el padre o el creador de ella - que su concepción se vuelve filosófica, es decir, crítica y racional; y, con Aristóteles, que empieza a vislumbrarse un tratamiento del tema que puede considerarse precientífico, pues escribe varios estudios propiamente sobre ello.

Con los romanos (principalmente con Cicerón), se denomina a la ética como philosophia morun y así es como, hasta la actualidad, se ha concebido como, grosso modo, una disciplina de la filosofía que mantiene constantemente, una reflexión crítica y racional sobre la moral.

Desde sus inicios, es indiscutible que la ética esté ligada a la moral, pero concebida como costumbres no deja claro sobre qué o a cuáles costumbres se refiere; en un sentido neutro, hay muchas, buenas y malas, pero la ética como disciplina que tiene como objeto de estudio a la moral, pretende examinar, reflexionar e, incluso (como en el caso de la deontología), establecer normas sobre los hábitos; pero, ¿cuáles?, para Guariglia (2007), estos a las que hace referencia la ética son las conductas positivas dentro de un grupo social específico: 
Al hablar, pues, de la existencia de una determinada moral positiva en el interior de un grupo social, estamos indicando que ese grupo comparte una determinada orientación evaluativa con respecto a sus acciones, en razón de la cual éstas son comprendidas, reconocidas y apreciadas por los miembros integrantes del mismo, los que, dicho de otro modo, comparten un standard evaluativo común. (p. 12)

Entonces, entendiendo moral como el comportamiento compartido, esperado, normado, deseado, dentro de un grupo social, ahora salta la cuestión de ¿por qué ser moral? La respuesta a esta pregunta se puede encontrar a través de la historia del pensamiento occidental, y establece todo lo que se ha reflexionado sobre ello, es decir, representa la ética de occidente.

¿Por qué ser moral? Algunas de las respuestas a esta pregunta son las siguientes: para Sócrates se debía serlo porque ennoblece la vida y constituye el bien humano; para Platón, ello procuraría el mejor tipo de vida para las personas; para Aristóteles, porque se logra el último fin de

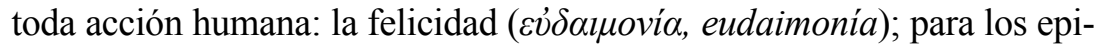
cúreos, ser moral concede el máximo placer (tranquilidad del ánimo).

Para la ética cristiana, porque la moral y los mandamientos divinos son de cumplimiento obligatorio; para Thomas Hobbes, porque sino, habría una guerra entre todos, para esto es necesario un contrato íntegro y mutuo, supervisado por un soberano absoluto; para David Hume, porque los seres humanos tienen simpatía, sentimientos hacia lo honorable, no cumplirlo sería ir en contra de su naturaleza; para Immanuel Kant, por el deber mismo, la sola razón dicta lo que es honesto en todo tiempo y lugar; para Jeremy Bentham, porque implicaría aumentar o lograr el mayor bien y felicidad en general (principio de utilidad).

Para la mayoría de los filósofos analíticos, los enunciados morales carecen de sentido, pero si se les concibe desde un punto de vista emotivo (no descriptivo) tienen un significado prescriptivo sobre los actos humanos, es decir, representan una guía para modificar las conductas; para John Rawls, ser moral implicaría justicia, si todos admiten, bajo un contrato, los principios de justicia, entonces ninguna persona será sacrificada en beneficio del interés de otro (Norman 2008). 


\section{La enseñanza de la ética en Costa Rica}

Me conformaría con que un joven o una joven saliera de su formación de bachillerato sabiendo cómo se razona en el terreno moral, cuál es la forma de razonamiento que hay en la moral, más que teniendo un decálogo determinado; teniendo la capacidad de razonar y de argumentar en el terreno moral.

(Savater, 2000, p. 225)

En Costa Rica, el sistema educativo público delega la formación de la moral a las familias de cada estudiante. Es decir, le da preferencia a la enseñanza informal que a la formal (programada, organizada, oficial, obligatoria, etc.) de este tema. Es necesario advertir que la moral no es un aspecto humano estrictamente cognoscitivo, por lo que no se puede enseñar como se hace con las partes del cuerpo o los números. Como se anotó anteriormente, esta se refiere más bien a costumbres positivas, las cuales se desarrollan principalmente, en el hogar (o lugar donde se convive o socialice desde el nacimiento), ya que es donde más pasan el tiempo las personas durante su vida.

Sin embargo, el sistema de educación no por esto debería dejar de lado el diagnóstico, la formalización, la sistematización y la programación educativa de este aspecto humano. Más bien, le correspondería tener la intención de brindar la posibilidad de que las personas reflexionen críticamente sobre la moral; en otras palabras, ofrecer una formación ética, pues esperar que lo íntegro del hogar sea de calidad nada más por ser de la familia, es una esperanza ilusoria, ya que esta no tiene un programa formal, no es sistemática y generalmente, la mayoría de los encargados (el padre y la madre) no han sido formados en el tema ético.

Ante esto último, Piaget (1984), menciona lo siguiente en su estudio sobre el criterio moral en el niño: "naturalmente, la mayoría de los padres son mediocres psicólogos y practican la más impropia de las pedagogías morales" (p. 161). La moral necesita ser reflexionada racionalmente en un contexto educativo para que así pueda ser convertida en ética, si no es así, se estaría ante una dogmática, impuesta, tradicional o no razonada con base en el momento, espacio, circunstancia, etc. Una sociedad ética, se logra, solamente, en conjunto (familia-escuela-comunidad) y desde edades tempranas, para que así desde los inicios de la 
formación de una persona, esta crezca con un proceso educativo (formal) del cual es juez y parte.

La reflexión racional sobre la moral debería tratarse con el mismo interés, prioridad y dedicación que se le tiene a las ciencias u otras materias académicas, y no menos. Pues de nada sirve en una sociedad que pretenda ser ética y justa, un profesional exitoso que carece de formación en el razonamiento de la integridad.

La decisión político-educativa de delegar la enseñanza de la moral a las familias de cada estudiante puede entenderse por razones como: uno, la de no tener que incurrir en más materias, profesionales, recursos, etc., pues ya existen disciplinas como religión, estudios sociales, cívica y otras que tocan el tema.

Dos, por respeto a la tutela de los encargados legales de cada estudiante; tres, por la confianza en la educación que se le brindan a los alumnos desde los hogares (por ende los medios, la creencia religiosa, la comunidad); cuatro, por la opinión de que la moral no es un tema tan necesario en la población estudiantil como para encargarse formalmente de este, entre otras razones.

¿Qué pasaría si las familias no son capaces de llevar a cabo esta tarea?, si la situación comunal o religiosa de la persona estudiante no es la idónea; si se es parte de un núcleo familiar con una moral distinta a la que el gobierno espera, como pueden ser grupos indígenas, hogares con credos distintos a los comunes en Costa Rica, etc.

En el caso de la ética profesional (entendida como aplicada o deontológica), es común su enseñanza formal a partir de la educación superior, por lo que esta queda relegada generalmente, a las personas que asisten a la universidad. En el país, parece ser que existe la idea generalizada de que todo profesional, por el hecho de serlo, es moralista, aplica la ética en su oficio.

Ante este panorama, queda en el lector contestar las siguientes preguntas: ¿Es justificado y necesario, o no lo es, invertir fondos en la programación y en la puesta en práctica de una enseñanza formal de la ética (como reflexión racional de la moral) desde tempranas edades?

¿Es mejor seguir invirtiendo prioritariamente en programas de enseñanza formal de temas intelectuales y técnicos, como el lenguaje, la historia, la biología, la matemática, la contaduría, la computación, los idiomas, etc.? ¿Se puede confiar en que las familias costarricenses brinden una adecuada formación moral a sus hijos como para no ver 
necesaria su reflexión dentro de las instituciones educativas? ¿Será cierto que todo profesional, solo por serlo, es ético?

Ante esto, Savater (2000) sostiene que:

...la educación y la educación ética son partes imprescindibles de cualquier formación humana. No se puede formar solamente a las personas desde el punto de vista laboral; formarles para que sepan apretar botones o para que cumplan funciones más o menos gestoras, sin haberles formado la capacidad de convivencia y ciudadanía, que no surge naturalmente de las personas. (p. 219)

En el caso del sistema de educación pública superior de Costa Rica, que es de carácter autónomo, la enseñanza de la ética es común en cursos conocidos como generales (obligatorios para todas las carreras) y no es tan habitual en los de carrera nombrados como ética profesional (enfocado en cada especialidad).

En estas instancias educativas, es frecuente que la ética se enseñe en algún nivel de cada carrera universitaria, ¿cómo se hace y si hay una incidencia de esto, en cada profesional que se egresa?, es una pregunta cuya respuesta se debería evidenciar en la sociedad, principalmente en la praxis, las actitudes y las costumbres que demuestren los profesionales graduados de las universidades públicas.

Con respecto a las universidades privadas, es muy común que se impartan cursos de ética profesional en las distintas carreras, más aún en el nivel de grado y posgrado, pero al igual que las públicas, también se carece de un control, una articulación e informes específicos sobre la incidencia de esta materia en la vida profesional futura de los egresados.

Después de que una persona se gradúa de cualquier universidad, debe (en el mejor de los casos) colegiarse a su respectivo gremio profesional, el cual tiene (o debería tener) un código de ética y una comisión que vele por su cumplimiento, pero en el país no es obligatoria la colegiatura en algunos casos (como el de los maestros y los periodistas), además, no hay un informe nacional sobre la situación moral de los distintos profesionales. Mucho menos hay informes de todos los ciudadanos no profesionales o de la población en general.

En Costa Rica, por como está planificada la educación, parece que la parte técnica de un profesional preocupa más que la moral y ética. Esto puede invitar a pensar que existe mayor preocupación por 
la obtención de un título y de un trabajo con un salario competente, que porque una persona sea un mejor ciudadano, hijo, esposo, amigo, compañero, etc.

Tal vez, esto se justifique por la idea, anteriormente mencionada, de que, si se es una persona titulada, se es moralista. Una vez más es válida la pregunta ¿será cierto que todo profesional, solo por serlo, es ético? ¿Incluso si ha cursado estudios de ética profesional en la universidad?

Si se hiciera un ejercicio mental como el siguiente: si un costarricense que sigue las noticias y que normalmente utiliza servicios públicos y profesionales de forma privada, se preguntara cuál es su valoración de la ética y la moral de los ciudadanos o de los profesionales costarricenses, ¿cuál sería su percepción?, ¿se obtendrá una respuesta alentadora?

Y es que es común escuchar de los malos tratos de algunos profesionales hacia su clientela, la corrupción en la política, sobre el poco esmero de algunos funcionarios en la labor pública, la escasa transparencia en asuntos de interés nacional, la competencia desleal, el irrespeto o la discriminación por la diversidad de opiniones, religión, nacionalidad, sexo, etc.

Esto solamente haciendo referencia a los profesionales o trabajadores de cualquier índole, pero si se analizara también la parte moral de los costarricenses como seres humanos, como ciudadanos, ¿cuál va a ser el panorama? ¿Se puede decir que la mayoría de la población es honesta, trabaja con esmero?

¿Son estas personas buenos amigos, son fieles a los compromisos de pareja, son sensibles a las injusticias, se informan sobre la realidad social y demuestran un civismo activo?, o sea ¿aportan ideas, soluciones o acciones para mejorar el país, etc.? Las respuestas a estas preguntas dependen de la experiencia de cada uno sobre este tema en Costa Rica.

Ante esto más preguntas saltan a la vista: ¿es necesaria la reflexión racional sobre la moral desde tempranas edades, por ejemplo, desde el primer grado de la educación general básica y de manera obligatoria? Es extraño pensar que es formal, sistemático y obligatorio aprender a leer, escribir, sumar, restar, multiplicar, cantar el himno, saber sobre el método científico, sobre el héroe nacional, etc., pero no es formal, sistemático, ni obligatorio aprender ética. 
No se ve como necesario reflexionar racionalmente sobre temas como la verdad y la mentira en distintos panoramas, el bien y el mal de las acciones humanas y sus consecuencias, los efectos de callar delitos, lo que es justo o no, según ciertas situaciones, lo que debe cambiar o no en las prácticas de vida de las personas, etc.

Para el aspecto intelectual y técnico, existe en Costa Rica una estructura educativa bien organizada desde el preescolar hasta la universidad con diagnósticos, planes, evaluaciones, materias, profesionales a cargo en cada etapa, etc., pero para la dimensión ética no hay diagnósticos, planes, evaluaciones, materias específicas, profesionales especializados en cada etapa, etc., que estén en relación con un seguimiento escalonado desde tempranas edades hasta la universidad. ¿Será que es más importante lo primero que lo segundo? ¿Podemos convivir en una sociedad intelectual y técnicamente competente, pero no éticamente consciente ni moralmente confiable?

No muchos costarricenses llegan a la universidad, por lo tanto, respecto de los no profesionales, ¿se puede decir que su formación moral (adquirida solamente desde el hogar) es suficiente para que estas personas sean buenas y confiables? Peor panorama se puede tener si se constatan dos situaciones más en relación con los que sí reciben educación ética: una que tiene que ver con la percepción común (a través de servicios públicos y privados, noticias, anécdotas, etc.) de que algunos profesionales cometen actos deshonestos (a pesar de que, en muchos casos, reciben educación ética); y, dos, que no hay estudios nacionales, ni locales que demuestren y confirmen la incidencia de los cursos o los códigos de ética en los egresados de las universidades e incorporados en los distintos colegios.

En otras palabras, si se realiza un balance entre lo que se escucha en noticias y en la calle, en cuanto a los actos poco moralistas por parte de profesionales, más la escasa información respecto a la incidencia de la enseñanza de la ética y los códigos deontológicos de los colegios, ¿se puede decir entonces que hay una buena atención, formación y evaluación de este aspecto humano en Costa Rica?

En el caso de los funcionarios del sistema público costarricense, estos cuentan también con la directriz D-2-2004 de la Contraloría General de la República (2004), y el decreto N. 33146 que contiene los Principios Éticos de los Funcionarios Públicos (2006), en los cuales se establecen pautas de comportamiento que serán observadas por 
una comisión de ética en la Función Pública para velar por su correcto cumplimiento.

Debido a esto, se puede decir entonces que estos trabajadores cuentan con más consideración y "vigilancia" del aspecto ético; pero no se puede indicar lo mismo en el caso de los que no son profesionales que trabajan en el sector privado, los cuales quedan sin educación formal acerca de este tema por no asistir a la universidad y, además, por no contar, en muchos casos, con directrices o códigos privados que los guíen y los normen como es el caso de la función pública.

En la educación general básica en este país, que es gratuita y obligatoria (ahora desde el materno), en ningún momento como materia específica, se insta a los estudiantes a reflexionar, discutir, dialogar, analizar, evaluar, etc., contenidos propiamente éticos durante un proceso escalonado. ¿Sería en vano una clase que busque desarrollar la conciencia moral durante todos estos años de estudio, que son gratuitos y obligatorios? ¿Es necesario esperar a que las personas sean adultas y vayan a la universidad para discutir sobre estos temas?

Si se analiza la planificación curricular del sistema educativo costarricense, parece ser que la conciencia ética es una habilidad que no se quiere desarrollar de manera formal, sistemática y obligatoria. No es el caso de las destrezas técnicas, las cuales están sobrevaloradas y cuentan con una importancia desmedida por sobre lo formativo (esto se expresa muy concretamente en políticas estatales como la "educación dual").

Al no haber un proceso de enseñanza paralelo con la moral y la ética, puede ser que muchos profesionales que son muy buenos en su labor técnica, sean altaneros, corruptos, poco honrados, con conductas discriminatorias, con poco afán de servicio o de civismo, etc., debido precisamente, a esta falta de formación. Siguiendo esta idea y la propuesta de los cuatro pilares de la educación, planteados por la UNESCO (Delors, 1997), se podría afirmar que en Costa Rica aprender a conocer y a hacer es más importante que aprender a ser y a convivir.

La enseñanza de valores ha sido una manera de asumir la instrucción de la ética en el Ministerio de Educación. Pero a estos se les ha planteado como un eje transversal respecto a las demás materias y, por lo tanto, no se están trabajando de forma directa. Además, no se les propone en un sentido moral, no se toman en cuenta en un programa de estudios o en un plan institucional educativo. 
Lo presentado en valores, más bien se muestran como conceptos que remiten a gestiones que se deben realizar porque sí, por lo que se les despoja del sentido moral, ya que esta disciplina no se debería enseñar en esta etapa como nociones o como normas que se deben seguir a la fuerza (como si fueran leyes), sino como acciones humanas que deben ser analizadas, discutidas, racionalizadas y acordadas que en la práctica provocan un bien más que un mal, para que así, los estudiantes de cualquier nivel se convenzan y participen de manera activa y crítica en el desarrollo de la conciencia ética de su país.

Esta conciencia moral no es un objeto de conocimiento, no es un concepto que adquirimos a través de la mediación sujeto-objeto. Es más bien una habilidad que se desarrolla y que, desde el punto de vista del autor de este texto, se debería de enseñar como una reflexión crítica constante y en conjunto con casos relacionados con el comportamiento humano, por lo que la ética debería tener estatus de materia, estar formalizada, programada, evaluada, obligatoria, etc., dentro del currículo educativo nacional.

Siguiendo con el tema de los valores, existen varios tipos de estos. En el caso de los cívicos, hay una materia en específico que se encarga de ello, para los religiosos también, igual que para los que representan contenidos de estética, pero para los centrados en la ética como tal (como por ejemplo el diálogo crítico sobre cuestiones de bioética, ambiente o leyes; la humildad como virtud, la honestidad ante diversos contextos, el papel de la responsabilidad hacia los compromisos adquiridos, el análisis de la verdad y la mentira, según distintos panoramas; la reflexión en torno a la noción de justicia, los límites de la libertad de cada quien en distintos lugares, el respeto a la diversidad, la búsqueda del sentido de la felicidad; etc.), no existen ni programas enfocados hacia ellos.

Desde hace muchos años, se habla de crisis de valores y los casos de corrupción y los malos tratos de profesionales son comunes casi a diario en Costa Rica. Sin embargo, y a pesar de esto, no hay avances en el plano ético, ni propuestas bien elaboradas y sistematizadas para mejorar la situación moral del país.

Cada vez hay más atención a la enseñanza técnica en los colegios, casi todas las universidades tienen acreditadas las carreras de ingeniería, administración, economía, etc., más y mejor pagados puestos en relación con la tecnología, las finanzas, las redes, el comercio, 
la industria, los idiomas, etc.; pero, a la par de estos avances no hay un progreso en el tema de la moral, los valores y la ética. Junto con el progreso científico, tecnológico y económico, debe haber un avance en materia moral y ética, si no es así, no hay un crecimiento integral y el futuro puede no ser tan alentador.

\section{Planes de enseñanza de la ética en Costa Rica}

Una de las cosas que me parece más pavorosa de los libros de ética es convertirlos en una especie de autoayuda, que dicen qué hay que pensar. Piense usted lo que quiera, pero piénselo. Lo único que me parece ético es suscitar la necesidad de que las cosas hay que pensarlas

(Savater, 2000, p. 215)

En el preescolar, los distintos valores morales y demás aspectos humanos se desarrollan de manera integral conforme a un plan y una docente especialista a cargo. Esta primera etapa, que es gratuita y obligatoria por ley, está bien organizada, sistematizada, programada y desarrollada de manera correlacionada con los siguientes niveles de la educación.

Durante la administración 2010-2014 de Leonardo Garnier, exministro de educación, se planteó lo siguiente en el programa de estudio de preescolar:

El objetivo que este programa establece para la Educación Preescolar, radica en el desarrollo de todas las potencialidades e intereses de nuestros niños y niñas, al tiempo que se satisfacen sus necesidades biológicas, emocionales, cognitivas, expresivas, lingüísticas y motoras, a través de un abordaje pedagógico integral. $[\ldots]$

Desde su integralidad, se ha nutrido de la visión que ha permeado muchas de las reformas impulsadas en los últimos años, incorporando los valores de la ética, la estética y la ciudadanía... (MEP, 2014b, p. 6)

En preescolar, se podría decir que se cumple con la necesidad de formar, de manera integral, el aspecto ético y moral de los futuros 
ciudadanos. Sin embargo, los niños y las niñas al llegar a la primaria y, posteriormente, a la secundaria, el tema de los valores y el sentido de la integridad se pierde debido a la fragmentación del sistema educativo en diversas materias que están priorizadas y enfocadas hacia el desarrollo cognoscitivo más que a cualquier otro.

En preescolar, el currículo educativo está integrado y toma en cuenta todos los aspectos humanos, pero desde primaria en adelante el plan de estudios se fragmenta en distintas materias académicas y no es comprensible que el tema de los valores, de la ética y la moral, no tenga al menos su propia asignatura como sí lo tiene la parte cognitiva (español, matemáticas, ciencia, estudios sociales), motora (educación física), estética (artes plásticas), espiritual (religión), etc.

La "solución" del Ministerio ante la necesidad de formar la parte ética y moral de los niños y las niñas de primaria en adelante, ha sido la elaboración de propuestas o estrategias para tomar en cuenta este aspecto, pero desde los planes de las demás materias de la enseñanza. Por ejemplo, la idea de la transversalidad de los valores fue integrada en los trasanteriores programas de enseñanza de las distintas disciplinas de la educación nacional.

Bajo la justificación de no saturar o fragmentar demasiado con más programas de estudio, el exministro de educación Manuel Antonio Bolaños formuló esta transversalidad, para primaria y secundaria, para hacerle frente al tema de la ética y los valores que, precisamente, se pierde después de la educación preescolar (MEP, 2004).

Esta noción plantea los valores como eje transversal de todas las demás materias. Se podría pensar que se trata de una buena idea: integrarlos a todas las disciplinas, pero imaginar que un docente de matemáticas, o de cualquier otra asignatura, va a trabajar el tema de los valores de una manera apropiada, con el tiempo adecuado y con la misma experticia que lo puede hacer un especialista en lo ético, deja muchas dudas.

Trabajar de forma lo más integral posible las distintas materias debería ser lo idóneo, independientemente de la propuesta de la transversalidad, pero también debería de existir una asignatura específica en la que se aborde de manera especial, profesional, programada, sistematizada, etc., el tema de la ética y la moral.

Asimismo, se podría citar la propuesta "Ética, estética y ciudadanía" planteada durante la administración del exministro Leonardo 
Garnier. Esta es parte, principalmente, de los programas de Estudios Sociales y Cívica de primaria (2013), de Estudios Sociales de secundaria (2014a) (ya descontinuado a partir del 2016) y de Educación Cívica para secundaria (2009).

En esta propuesta, se argumenta que se le hace frente a la falta de recursos para abordar estos temas, a la dificultad de crear más materias, a la "pérdida de valores", la falta de formación integral, etc. Sin embargo, se sigue promoviendo la enseñanza de la ética y los valores como una transversalidad que debería tratarse en todas las asignaturas (como lo había propuesto el ministro anterior: Manuel Antonio Bolaños) o como un aspecto que viene a ser parte principalmente de disciplinas como las de Estudios Sociales y Cívica.

El nuevo programa de Filosofía del MEP para la educación diversificada (2017a), plantea la formación de criterios éticos ante varias situaciones de aprendizaje, pero se trata de un plan que no solo integra la ética, sino las demás áreas de la filosofía como la Antropología Filosófica, la Lógica, la Estética, la Epistemología, el Pensamiento Social. Además, es un método para undécimo año de secundaria que en muchos casos no se brinda en todas las instituciones y que no cuenta con una articulación y sistematización previa, ni posterior con otros procedimientos educativos.

Existen algunos planes de especialidades técnicas de la educación nacional que integran dentro de sus programas la ética, por ejemplo, en los talleres exploratorios que se imparten en los colegios técnicos profesionales del país, en el tercer ciclo de la Educación General Básica se encuentran temas o asignaturas que están relacionadas con la ética en materias como contabilidad, administración y operación aduanera, entre otras.

En el actual programa de educación para adultos del III nivel, existe un módulo llamado Ética profesional; dentro del plan del colegio técnico artístico Felipe Pérez existe una asignatura llamada Psicología y ética; en los programas de estudios de Educación para la Afectividad y Sexualidad Integral para el tercer ciclo y educación diversificada, existen temas como el de la ética relacional y ética de mínimos (MEP, 2017b).

Sin embargo, la planificación y la enseñanza de la ética no se evidencian en todas las especialidades, los módulos, los colegios o los talleres, solo es en algunos, además, este aspecto no está articulado, ni 
es sistemático en el método educativo nacional. La formación moral que se brinda es aislada y no representa ningún eslabón de seguimiento continuo.

De manera independiente, existen planes afines a la ética, como el Programa Nacional de Convivencia, MEP (2012), que, a través de una guía práctica, tiene como objetivo promover y ejecutar acciones para fortalecer las relaciones de coexistencia en todos los centros de estudio del país.

Desde la perspectiva del autor, este es un buen programa para la moral y está planteado de forma independiente; sin embargo, carece de estatus de materia, no se aplica en todas las instituciones de Costa Rica y contempla de manera muy enfocada el tema de la convivencia, el cual es solo uno de muchos que tienen relación con los valores. Este plan podría ser parte de uno mayor en el que se desarrolle el tema de la ética, a través del abordaje práctico durante toda la educación general básica, pero esto no existe en el país.

Otros programas son el de Detección e Intervención temprana de adicciones y Aprendo a valerme por mí mismo del Instituto sobre Alcoholismo y Farmacodependencia; el de Educación para la Vida Cotidiana, el de Educación Vial, el de Interculturalidad y otros que, bien podrían ser parte de un plan general de ética y moral en el que se promuevan la práctica de valores y la reflexión, lo más racional posible y otros temas más, pero no existe tal opción.

Lo mismo ocurre en algunas escuelas y colegios privados del país, estos cuentan con materias llamadas ética y valores, pero generalmente, son impartidas por docentes de estudios sociales, cívica, religión, psicología, etc., y no responden a un programa general, de país, sobre alguna intencionalidad, guía o razón de ser de estos, en un sentido amplio, sistematizado, articulado e, idealmente, permanente, para toda la vida.

Desgraciadamente, muchos de estos asuntos de índole ético y moral se diluyen en estos planes particulares que no cuentan con un programa general que les dé fundamento, además, no todos tienen lecciones semanales, ni especialistas a cargo, por lo que verlos de manera aislada, sin un cronograma bien establecido y sin profesionales encargados de su puesta en práctica, es una tarea que, por no estar bien articulada, puede estarse perdiendo. 
En el caso de la enseñanza de valores en universidades (públicas y privadas), son comunes los cursos sobre ética profesional, introducción a la ética, bioética, ética ambiental, entre otros. Estos son más frecuentes en carreras como derecho, filosofía, teología, religión, educación, medicina; sin embargo, se les puede encontrar también, en planes de cualquier otra carrera. En el caso particular de la Universidad Nacional de Costa Rica, en la tabla 1 se va a reflejar los cursos propiamente de ética hallados en los planes de carrera que se pueden localizar en la página de la universidad https://www.una.ac.cr/, al cierre del año 2019.

\section{Tabla 1}

Cursos de Ética de la Universidad Nacional de Costa Rica

\begin{tabular}{|c|c|c|}
\hline Grado & Carrera & Cursos de ética \\
\hline Bachillerato & Bibliotecología Pedagógica & Ética profesional \\
\hline Bachillerato & Bibliotecología y Documentación & Ética profesional \\
\hline \multirow[t]{2}{*}{ Bachillerato } & Enseñanza de la Filosofía & Educación y ética \\
\hline & & $\begin{array}{c}\text { Introducción a los } \\
\text { problemas de la } \\
\text { ética }\end{array}$ \\
\hline Bachillerato & Enseñanza de la Religión & Ética teológica \\
\hline Bachillerato & Economía & $\begin{array}{c}\text { Ética y economía } \\
\text { (optativo) }\end{array}$ \\
\hline \multirow[t]{4}{*}{ Bachillerato } & Filosofía & $\begin{array}{c}\text { Introducción a los } \\
\text { problemas de la } \\
\text { ética }\end{array}$ \\
\hline & & Bioética \\
\hline & & $\begin{array}{l}\text { Ética ambiental } \\
\text { (optativo) }\end{array}$ \\
\hline & & $\begin{array}{l}\text { Ética médica } \\
\text { (optativo) }\end{array}$ \\
\hline Bachillerato & Teología & Ética teológica \\
\hline Bachillerato & $\begin{array}{l}\text { Música con énfasis en Ejecución y } \\
\text { Enseñanza del Instrumento }\end{array}$ & Ética profesional \\
\hline Bachillerato & Medicina Veterinaria & Bioética \\
\hline Bachillerato & Psicología & Ética \\
\hline
\end{tabular}




\begin{tabular}{|c|c|c|}
\hline Grado & Carrera & Cursos de ética \\
\hline Licenciatura & $\begin{array}{l}\text { Música con énfasis en Interpreta- } \\
\text { ción y Enseñanza de la Dirección } \\
\text { Coral }\end{array}$ & $\begin{array}{l}\text { Ética y currículum } \\
\text { musical }\end{array}$ \\
\hline Licenciatura & $\begin{array}{l}\text { Música con énfasis en la Interpreta- } \\
\text { ción y Enseñanza del Canto }\end{array}$ & $\begin{array}{l}\text { Ética y currículum } \\
\text { musical }\end{array}$ \\
\hline Licenciatura & $\begin{array}{l}\text { Educación con énfasis en Educa- } \\
\text { ción Rural, I y II ciclo }\end{array}$ & $\begin{array}{l}\text { Ética profesional y } \\
\text { docencia rural }\end{array}$ \\
\hline Licenciatura & Enseñanza de las Ciencias & Bioética \\
\hline Licenciatura & Orientación & $\begin{array}{c}\text { Marco ético-jurídico } \\
\text { de la orientación }\end{array}$ \\
\hline Maestría & Bioética & $\begin{array}{c}\text { Cursos obligatorios } \\
\text { del posgrado: } \\
\text { Bioética } \\
\text { fundamental } \\
\text { Métodos de la } \\
\text { bioética } \\
\text { Bioética clínica } \\
\text { Ética de los confines } \\
\text { de la vida } \\
\text { Ética aplicada y alta } \\
\text { tecnología } \\
\text { Teorías y sistemas } \\
\text { éticos } \\
\text { Ética de la inves- } \\
\text { tigación con seres } \\
\text { vivos } \\
\text { Cursos optativos: } \\
\text { Bioética y gestión } \\
\text { en salud } \\
\text { Ética y ambiente } \\
\text { Seminario de bioéti- } \\
\text { ca aplicada }\end{array}$ \\
\hline
\end{tabular}




\begin{tabular}{ccc}
\hline Grado & Carrera & Cursos de ética \\
\hline Maestría & Estudios Teológicos & $\begin{array}{c}\text { Dimensiones éticas } \\
\text { en los sinópticos } \\
\text { Ética del amor y la } \\
\text { salud en perspectiva } \\
\text { de género } \\
\text { Propuestas éticas en } \\
\text { Pablo y Juan }\end{array}$ \\
Maestría & Ciencias Marinas y Costeras & $\begin{array}{c}\text { Seminario de ética, } \\
\text { ciencia y tecnología }\end{array}$ \\
Maestría & Estudios de Cultura & $\begin{array}{c}\text { Ética y sociedad en } \\
\text { Centroamérica }\end{array}$ \\
Maestría & Centroamericana & Liderazgo y ética \\
& profesional \\
Maestría Educativa con énfasis en & Liderazgo & Sociedad, ética y \\
Humanismo, Sociedad y Ambiente & ambiente \\
Maestría & Planificación & Ética y desarrollo \\
Maestría & Responsabilidad Social y & Ética y gobernanza \\
Maestría & Sostenibilidad & Administración de Justicia Enfoque \\
& Socio-Jurídico con Énfasis Civil, & Seminario de ética \\
& Penal o Relaciones Familiares & jurídica \\
\hline
\end{tabular}

Nota: elaboración propia.

De acuerdo con la tabla 1, de alrededor de las sesenta y cuatro carreras que se ofrecen en esta universidad, solo en quince se brindan cursos de ética en sus planes. Sin embargo, no todos estos son obligatorios como parte del plan de estudios, algunos son optativos, es decir, que pueden ser elegidos o no.

En cuanto a los posgrados, de alrededor de los cincuenta y tres, solo en nueve se ofrecen veinte cursos de ética, entre ellos algunos optativos. De estos, diez son parte de la maestría en bioética que se conlleva con la Universidad de Costa Rica, y los otros se dividen entre ocho de los cincuenta y tres posgrados que se pueden visualizar en la página https://www.una.ac.cr/, al cierre del año 2019.

En el caso de los cursos de estudios generales de la Universidad Nacional de Costa Rica, los cuales, de un total de sesenta y dos, que 
ofrecen las cuatro disciplinas (ciencias sociales, filosofía y letras, ciencia y tecnología, y arte), los estudiantes deben elegir cuatro en al menos tres de dichas áreas.

De estos sesenta y dos cursos, no todos están disponibles en un mismo ciclo lectivo, además, son obligatorios, pero de todos los que se presentan se puede escoger uno $\mathrm{u}$ otro, o sea que, bien los estudiantes podrían no elegir ningún de ética y, además, si su carrera no brinda materias sobre este aspecto humano, se estaría egresando un profesional sin ninguna enseñanza formal (programada, especializada, enfocada, etc.,) en la moral.

De filosofía y letras, existen solamente tres clases que los estudiantes podrían escoger, si es el caso que se ofrecen durante un mismo ciclo, de estos son ejemplo los siguientes: Problemas y dilemas éticos de la era contemporánea, Ética frente a la globalización y Ética y filosofía. En cuanto a las disciplinas de ciencia y tecnología, solamente se brinda uno: Ética ambiental. De las demás áreas se carece de cursos sobre esta materia.

Por otro lado, en el nivel profesional es casi generalizado el uso de códigos morales en los distintos colegios profesionales, estos centros en muchas ocasiones facilitan capacitaciones, charlas o asesorías sobre este aspecto humano. Incluso cuentan con un juzgado de honor o comité de ética que califica el correcto o el incorrecto actuar moral de los profesionales de cada colegio. Estas audiencias también se pueden encontrar en los distintos partidos políticos y se les conoce como Tribunal de Ética y Disciplina.

También, como ya se mencionó, los empleados públicos cuentan con decretos, directrices, comisiones, etc., que velan por el apego a ciertas normas éticas. Desde el gobierno en algunas ocasiones se facilitan capacitaciones, charlas o asesorías sobre este tema a sus distintos funcionarios.

Por su parte, algunas instituciones nacionales autónomas o privadas tienen sus propios códigos de comportamiento y es común la divulgación de este aspecto entre sus trabajadores; sin embargo, no se podría afirmar que esto, ni lo que presentan los colegios profesionales o los partidos políticos en cuanto a la ética y la moral cuente como planes de formación de valores, más bien parecen más a normas sancionatorias que a procesos de educación en este aspecto. 


\section{¿Se puede enseñar la ética?}

En este apartado especial se va a analizar la posibilidad o no y, la efectividad o no, de la enseñanza de la ética. Respecto a las clases de ética que se brindan en las universidades, cabe hacer las siguientes preguntas: ¿puede un curso de esta materia incidir en la moral de una persona que no ha recibido enseñanza formal en este aspecto durante la infancia y la adolescencia?, ¿se debe enseñar como contenido intelectual: historia, normas, pensadores, tipos, teorías, etc.?, ¿o más bien con una metodología que se enfoque en la reflexión racional de casos que pretenden incidir en la conducta moral de las personas? ¿Es la enseñanza de la ética una introducción a la práctica de la reflexión racional acerca de la moralidad?, ¿o es una materia que remite a unas normas que simplemente hay que seguir como si se tratara del estudio de la Constitución Política o de alguna ley?

Contestar agudamente estas preguntas excede los objetivos de este trabajo, pero ante la simple interrogante de si se puede enseñar ética, ya sea en la universidad o, incluso, desde edades tempranas, se puede considerar lo siguiente: la educación de la moral no debería concebirse como un tema intelectual, ni como una norma que se deba seguir obligatoriamente.

Enseñar ética debería ser una práctica en la que haya libertad de expresión argumentada que indague no principalmente, el conocimiento, ni el apego obligatorio a los preceptos sociales, sino que, por un lado, busque representar un espacio de diálogo en el que se analicen situaciones morales para una mejor comprensión de la vida humana y de las reglas de conducta que previamente se han establecido.

Y por otro lado, busque representar la oportunidad de reflexionar racionalmente estas conductas humanas para actualizar, crear y ser juez y parte de la vida práctica de la sociedad en el momento en el que se está viviendo. Como lo menciona Guisán (1995): "El ámbito de la ética es un ámbito de libertad y creatividad, amén de un discurso razonado acerca de la justificación de toda suerte de normatividad (la moral cotidiana, la norma jurídica, los códigos formales e informales, etc.)" (p. 18).

Según Mauri (2015), hay quienes pueden afirmar que temas prácticos como el de la moral son un fenómeno inefable, emotivo y subjetivo que no puede ser racionalizado, por lo tanto, no se puede enseñar ni argumentar en torno a ella. Sin embargo, para esta autora la 
ética tiene un objeto de estudio: la moralidad, por lo que sí se puede analizar y, debido a esto, llegar a conclusiones racionales y propuestas de enseñanza formal que representen una manera de revertir conductas perjudiciales para la sociedad.

No obstante, si no se piensa, ni se discute formalmente sobre estos temas en las distintas instituciones de educación, la moral puede llegar a ser una cuestión impositiva, absurdamente tradicional o dogmática, perdiendo además la esencia de la ética: ser una reflexión racional sobre la vida práctica, es decir sobre los valores.

Por lo anterior, este aspecto humano debería ser libre de pensarse, analizarse y discutirse en una institución de enseñanza, a través de un proceso formal y colectivo continuo desde tempranas edades, para que de esta manera se concrete en las personas una noción clara y racional sobre lo que es la moral y la ética. Estos temas concebidos como teoría, conocimiento, normas o discurso sin una práctica educativa que promueva su reflexión crítica, durante las diferentes etapas del desarrollo de un individuo, no tiene sentido.

Según Mauri (2015), la actuación moral está emparentada con el pensar y por esto es de esperarse que toda persona que se ejercite en la reflexión sobre esos temas vaya a estar más cerca de la práctica de los principios éticos que los que no se adiestren en este aspecto. Esto es algo que se ha afirmado desde la Grecia antigua con Aristóteles (1985):

Así pues, puesto que el presente estudio no es teórico como los otros (pues investigamos no para saber qué es la virtud, sino para ser buenos, ya que de otro modo ningún beneficio sacaríamos de ella), debemos examinar lo relativo a las acciones, cómo hay que realizarlas, pues ellas son las principales causas de la formación de los diversos modos de ser. (p. 160)

Y hasta la época actual con Piaget (1984), quien menciona, en su estudio sobre el criterio ético en el niño, que "hay una relación entre la reflexión moral y la práctica, bien porque aquélla sirve de reflexión a ésta, bien porque la reflexión constituye una toma de conciencia de la acción" (p. 96).

Ante esto, se pueda afirmar entonces que es posible una enseñanza de la ética centrada en la reflexión racional de los valores en cualquier etapa de la educación. Y es posible también, que esta formación 
signifique un desarrollo de la conciencia moral y esto represente una incidencia importante en la vida práctica de las personas.

\section{Conclusión}

Como se pudo observar, la enseñanza de la ética en Costa Rica no está bien establecida, ni articulada durante las diferentes etapas de la educación nacional. No hay evaluaciones, ni informes sobre el tema y su progreso en el país. Ni la ética (como reflexión de la moral) ni la moral (como conductas positivas de vida) cuentan con planes formales y obligatorios de enseñanza durante la educación general básica.

Existen propuestas y programas en primaria y secundaria que abordan algunos valores o temas que tienen relación con un ideal de moral de la sociedad, pero estos, en muchos casos, son secundarios, no obligatorios o están integrados a otros planes y al tiempo efectivo de otras materias, además, no se plantean como acciones humanas que requieren de una reflexión crítica para comprenderlas y racionalizarlas, sino como actitudes que los estudiantes deben desarrollar por mera adaptación al sistema de vida del momento, lo cual hace que se pierda el sentido ético de la moral.

Solo en preescolar y en la educación superior se puede decir que existen planes formales y obligatorios que toman en cuenta con más tino el tema de la moral y la ética. Pero, cualquier persona sensata y con el mínimo conocimiento de lo que son estos contenidos estaría de acuerdo con la necesidad de prestarle más atención y darle prioridad a su formación, no solo para los que se están integrando como profesionales, sino también desde el primer grado de la primaria y hasta el último de la secundaria, pues de nada serviría estudiar ética en la facultad, si no se establecieron bases sólidas de este aspecto humano en las etapas anteriores.

Como se expuso anteriormente, los exministros de educación no quisieron formalizar, programar ni poner en práctica la ética como materia, porque argumentaron falta de recursos, desorganización y saturación con las demás asignaturas, etc.; pero, si volvemos a la idea de si es necesario o no, solo falta ver noticias sobre la realidad política y social del país, tomar un servicio público, ir a un estadio de fútbol, o leer comentarios en redes sociales, para darse cuenta de que esta materia es igual o más importante y prioritaria que cualquier otra. 
¿Cuál es el panorama de la enseñanza de la ética en Costa Rica? ¿Se puede confiar en la educación moral que dan las familias costarricenses, las comunidades o las diferentes religiones? ¿Son suficientes los esfuerzos que hace el Ministerio de Educación para tratar de formar este aspecto humano, o hace falta más? ¿Será en vano una programación y materia formal y específica que aborde, con sus particularidades, la enseñanza de la ética desde tempranas edades hasta ligarlo con la universidad?

Estas y otras preguntas inspiraron este trabajo y durante su desarrollo se ha pretendido analizar el tema de la ética en Costa Rica, para abrir el debate hacia la necesidad de que haya en el país educación formal, obligatoria y específica sobre ello. Así, no solamente haya buena formación en lo lógico-matemático, lingüístico, histórico, técnico, etc., sino también del aspecto ético y, por ende, moral.

Finalmente, se concluye insistiendo en la idea, anteriormente mencionada, de que el progreso de la humanidad no se logra solamente a través de avances científicos, tecnológicos y económicos, sino también, de manera conjunta, con desarrollos en el tema de la moral y la ética.

\section{Referencias}

Aristóteles (1985). Ética Nicomáquea. Ética Eudemia. Madrid: Gredos. Contraloría General de la República de Costa Rica (CGR). (2004). Directrices generales sobre principios y enunciados éticos a observar por parte de los jerarcas, titulares subordinados, funcionarios de la Contraloría General de la República, auditorías internas y servidores públicos en general. Recuperado de http://www.pgrweb.go.cr/scij/Busqueda/Normativa/Normas/ nrm_texto_completo.aspx?param $1=$ NRTC \&nValor $1=1 \& n$ Valor $2=53925 \&$ nValor $3=58925 \&$ strTipM $=\mathrm{TC}$

Delors, J. (Comp.). (1997). La educación encierra un tesoro. México D. F.: Ediciones UNESCO.

Guariglia, O. (Ed.) (2007). Cuestiones morales. Madrid: Trotta.

Guisán, E. (1995). Introducción a la ética. Madrid: Cátedra.

MacIntyre, A. (1998). Historia de la ética. Barcelona: Paidós.

Mauri, M. (2015). La enseñanza de la asignatura de ética en la universidad: controversia sobre su finalidad. Revista FORUM, 1, 227-235. 
Ministerio de Educación Pública de Costa Rica (MEP). (2004). Transversalidad en el currículo educativo costarricense. San José: Imprenta Nacional.

Ministerio de Educación Pública de Costa Rica (MEP). (2009). Programa de Estudio de Educación Cívica para III ciclo de la Educación General Básica y ciclo Diversificado. San José: Imprenta Nacional.

Ministerio de Educación Pública de Costa Rica (MEP). (2012). Programa Nacional de Convivencia. San José: Imprenta Nacional.

Ministerio de Educación Pública de Costa Rica (MEP). (2013). Programas de Estudios Sociales y Educación Cívica del I y II ciclo de la Educación General Básica. San José: Imprenta Nacional.

Ministerio de Educación Pública de Costa Rica (MEP). (2014a). Programa de Estudio de Estudios Sociales para III ciclo de la Educación General Básica y ciclo Diversificado. San José: Imprenta Nacional.

Ministerio de Educación Pública de Costa Rica (MEP). (2014b). Programa de Estudio Educación Preescolar. San José: Imprenta Nacional.

Ministerio de Educación Pública de Costa Rica (MEP). (2016). Programa de Estudio de Estudios Sociales para III ciclo de la Educación General Básica y ciclo Diversificado. San José: Imprenta Nacional.

Ministerio de Educación Pública de Costa Rica (MEP). (2017a). Programa de Estudio de Filosofía. Educación Diversificada. San José: Imprenta Nacional.

Ministerio de Educación Pública de Costa Rica (MEP). (2017b). Compendio de ofertas y servicios del sistema educativo costarricense. Recuperado de https://www.mep.go.cr/sites/default/files/page/ adjuntos/compendiomep-2016dpi.pdf

Norman, R. (2008). Historia de la filosofia moral. En T. Honderich (Ed.), Enciclopedia Oxford de Filosofia (pp. 812-817). Madrid: Tecnos.

Piaget, J. (1984). El criterio moral en el niño. Barcelona: Martínez Roca.

Poder Ejecutivo, Gobierno de Costa Rica. (31 de mayo del 2006). Decreto $N .^{\circ} 33146$. Los principios éticos de los funcionarios públicos. Recuperado de http://www.pgrweb.go.cr/scij/Busqueda/ 
Normativa/Normas/nrm_texto_completo.aspx?param1=NRT$\mathrm{C} \&$ nValor $1=1 \&$ nValor $2=57282 \&$ nValor $3=62848 \&$ strTipM $=$ TC Savater, F. (2000). La educación es el momento adecuado de la ética. ¿De qué sirve la ética para los jóvenes? Revista Educere, 4(11), 215-226. 